\title{
Interventions for intermittent exotropia (Review)
}

\author{
Hatt SR, Gnanaraj L
}

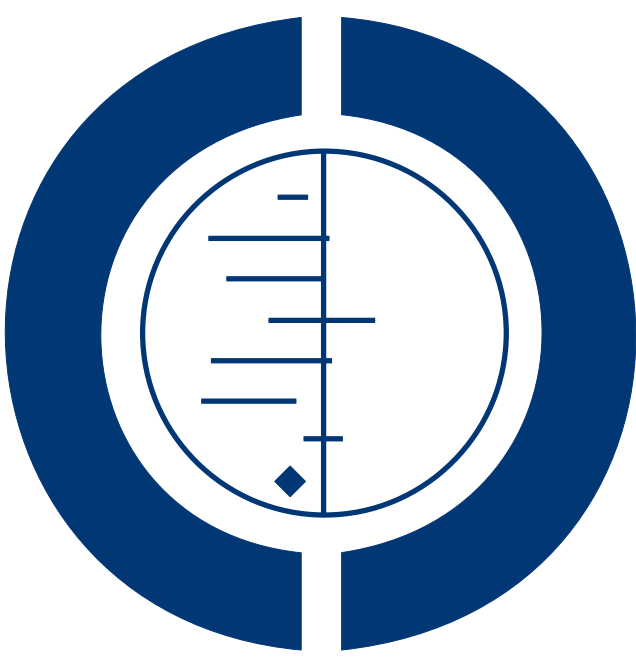

THE COCHRANE COLLABORATION $^{\circledR}$

This is a reprint of a Cochrane review, prepared and maintained by The Cochrane Collaboration and published in The Cochrane Library 2006, Issue 3

http://www.thecochranelibrary.com

\section{WILEY}


TABLE OF CONTENTS

HEADER . . . . . . . . . . . . . . . . . . . . . . . . . . . . . . . . . . . . 1

ABSTRACT . . . . . . . . . . . . . . . . . . . . . . . . . . . . . . . . . . . . . . . . . . . . . . .

PLAIN LANGUAGE SUMMARY . . . . . . . . . . . . . . . . . . . . . . . . . . . . . . . . . . . 2

BACKGROUND . . . . . . . . . . . . . . . . . . . . . . . . . . . . . . . . . . . . . . . . .

OBJECTIVES . . . . . . . . . . . . . . . . . . . . . . . . . . . . . . . . . . . . .

METHODS . . . . . . . . . . . . . . . . . . . . . . . . . . . . . . . . . . . . . .

RESULTS . . . . . . . . . . . . . . . . . . . . . . . . . . . . . . . . . . . . . . . . 7

DISCUSSION . . . . . . . . . . . . . . . . . . . . . . . . . . . . . . . . . . . . . 8

AUTHORS' CONCLUSIONS . . . . . . . . . . . . . . . . . . . . . . . . . . . . . . . . . . . . . . . . . .

ACKNOWLEDGEMENTS . . . . . . . . . . . . . . . . . . . . . . . . . . . . . . . . . 10

REFERENCES . . . . . . . . . . . . . . . . . . . . . . . . . . . . . . . . . . . . . . 10

CHARACTERISTICS OF STUDIES . . . . . . . . . . . . . . . . . . . . . . . . . . . . . . . . . . 14

DATA AND ANALYSES . . . . . . . . . . . . . . . . . . . . . . . . . . . . . . . . . . . 18

APPENDICES . . . . . . . . . . . . . . . . . . . . . . . . . . . . . . . . . . . . . 18

WHAT'S NEW . . . . . . . . . . . . . . . . . . . . . . . . . . . . . . . . . . . . . 20

HISTORY . . . . . . . . . . . . . . . . . . . . . . . . . . . . . . . . . . . . . . . 20

CONTRIBUTIONS OF AUTHORS . . . . . . . . . . . . . . . . . . . . . . . . . . . . . . . . . . . . . . . . . .

DECLARATIONS OF INTEREST . . . . . . . . . . . . . . . . . . . . . . . . . . . . . . . 21

INDEX TERMS . . . . . . . . . . . . . . . . . . . . . . . . . . . . . . . . . . . .

Interventions for intermittent exotropia (Review)

Copyright $\odot 2009$ The Cochrane Collaboration. Published by John Wiley \& Sons, Ltd. 


\title{
[Intervention Review]
}

\section{Interventions for intermittent exotropia}

\author{
Sarah R Hatt ${ }^{1}$, Lawrence Gnanaraj ${ }^{2}$ \\ ${ }^{1}$ Ophthalmology Research, Mayo Clinic, Rochester, USA. ${ }^{2}$ Sunderland Eye Infirmary, Sunderland, UK \\ Contact address: Sarah R Hatt, Ophthalmology Research, Mayo Clinic, Guggenheim 9, 200 1st St. SW, Rochester, MN 55905, USA. \\ sarahrhatt@gmail.com.
}

Editorial group: Cochrane Eyes and Vision Group.

Publication status and date: New search for studies and content updated (no change to conclusions), published in Issue 2, 2009.

Review content assessed as up-to-date: 24 November 2008.

Citation: Hatt SR, Gnanaraj L. Interventions for intermittent exotropia. Cochrane Database of Systematic Reviews 2006, Issue 3. Art. No.: CD003737. DOI: 10.1002/14651858.CD003737.pub2.

Copyright (C) 2009 The Cochrane Collaboration. Published by John Wiley \& Sons, Ltd.

\begin{abstract}
A B S T R A C T
Background

The clinical management of intermittent exotropia has been discussed extensively in the literature, yet there remains a lack of clarity regarding indications for intervention, the most effective form of treatment and whether or not there is an optimal time in the evolution of the disease at which any treatment should be carried out.
\end{abstract}

\section{Objectives}

The objective of this review was to analyse the effects of various surgical and non-surgical treatments in randomised trials of participants with intermittent exotropia, to report intervention criteria and determine the significance of factors such as age with respect to outcome.

\section{Search methods}

We searched the Cochrane Central Register of Controlled Trials (CENTRAL) (which contains the Cochrane Eyes and Vision Group Trials Register) (The Cochrane Library, Issue 4, 2008), MEDLINE (January 1966 to November 2008), EMBASE (January 1980 to November 2008), the UK Clinical Trials Gateway (UKCTG) and Latin American and Caribbean Literature on Health Sciences (LILACS) (January 1982 to November 2008). No language or date restrictions were placed on the searches. The electronic databases were last searched on 25 November 2008. We manually searched the British Orthoptic Journal, proceedings of the European Strabismological Association (ESA), International Strabismological Association (ISA) and American Academy of Paediatric Ophthalmology and Strabismus meeting (AAPOS). We contacted researchers who are active in the field for information about further published or unpublished studies.

\section{Selection criteria}

We included randomised controlled trials of any surgical or non-surgical treatment for intermittent exotropia.

\section{Data collection and analysis}

Each review author independently assessed study abstracts identified from the electronic and manual searches. Author analysis was then compared and full papers for appropriate studies were obtained.

\section{Main results}

We found one randomised trial that was eligible for inclusion. This trial showed that unilateral surgery was more effective than bilateral surgery for correcting the basic type of intermittent exotropia. 


\section{Authors' conclusions}

The available literature consists mainly of retrospective case reviews which are difficult to reliably interpret and analyse. The one randomised trial included found unilateral surgery more effective than bilateral surgery for basic intermittent exotropia. However, across all identified studies, measures of severity and thus criteria for intervention are poorly validated, and there appear to be no reliable natural history data. There is therefore a pressing need for improved measures of severity, a better understanding of the natural history and carefully planned clinical trials of treatment to improve the evidence base for the management of this condition.

\section{PLAIN LANGUAGE SUMMARY}

\section{Treatment for a type of childhood strabismus where one or both eyes intermittently turn outwards}

Strabismus is a condition in which the eyes are out of alignment, that is one eye looks straight ahead whilst the other eye turns inwards, outwards, up or down. In most cases of childhood onset strabismus the misalignment is present constantly, but in intermittent exotropia $(\mathrm{X}(\mathrm{T})$ ) an eye intermittently drifts outwards (exotropia), typically more so when looking into the distance, when tired or day-dreaming. When the child focuses on something close, the eye usually moves back to the centre. In $\mathrm{X}(\mathrm{T})$ ability to use the eyes together as a pair (binocular single vision) is typically retained during periods when the exotropia is controlled and the image from one eye is switched off or 'suppressed' when the exotropia occurs. Treatment for X(T) may be sought to improve the appearance of misalignment or may be instigated if there is concern that it is worsening with potential or actual loss of binocular single vision. Treatment typically consists of surgery on the muscles around the eye: it may be either on the outside muscle of both eyes or on the inside and outside muscle of one eye. Exercises to strengthen the muscles may sometimes be used; sometimes patching or glasses for short/ near sightedness can be tried. There is currently not a clear understanding of which treatments work most effectively and at what point any treatment should be given. We searched for studies where participants with $\mathrm{X}(\mathrm{T})$ had been randomised to receive treatment. The aim was to establish which treatments are most effective at correcting the exotropia without adversely affecting any pre-existing binocular single vision. The one included study in this review compared surgery on one eye to surgery on both eyes for the basic type of $\mathrm{X}(\mathrm{T})$ and found that surgery on one eye was more effective. There are many studies of $\mathrm{X}(\mathrm{T})$ in the current literature but the methods used do not allow reliable interpretation of the results. Furthermore there is a worrying lack of evidence regarding the natural history of $\mathrm{X}(\mathrm{T})$ and poor validation of measures of severity. There is a clear need for further randomised studies to provide more reliable evidence for the management of this condition.

\section{B A C K G R O U N D}

\section{Epidemiology}

Ocular misalignment (strabismus) develops in approximately $5 \%$ of developmentally normal children (Graham 1974). Of these approximately $25 \%$ present with an outward turning ocular deviation or exotropia (Jenkins 1992). The most common type of childhood onset exotropia is intermittent exotropia $(\mathrm{X}(\mathrm{T})$ ) (Mohney 2003), with a reported incidence rate of $32.1 / 100,000$ in children under 19 years of age in the United States of America (Govindan 2004) and occurring more frequently in Asian populations (Chia 2007; Matsuo 2005) in latitudes with greater sunlight (Jenkins 1992) and in females (Nusz 2005).

The term 'intermittent exotropia' may be used to describe any non-constant exotropia but it is typically (and throughout this review) used to describe the type of exodeviation that is present predominantly at distance fixation with or without deviation at near fixation. Pseudonyms include distance exotropia, divergence excess exotropia, periodic exotropia and exotropia of inattention. Intermittent exotropia is sometimes sub-divided into 'basic' and 'distance' subtypes but clinical characteristics are very similar for these sub-types of $\mathrm{X}(\mathrm{T})$ and, as investigation and management are also essentially the same (Cooper 1977), they are considered together in this review and jointly referred to as 'intermittent exotropia' or X(T).

\section{Natural history}

The natural history of $\mathrm{X}(\mathrm{T})$ is not well documented. An early study by von Noorden (von Noorden 1966) is quoted (von Noorden 2002) as finding $75 \%$ of patients progressing over an average of 
three years, but the original report is unavailable. Conversely, a contemporary report by Hiles (Hiles 1968) reported six year follow up angle data on $\mathrm{X}(\mathrm{T})$ patients who 'for various reasons were not operated upon' and found $81 \%$ showed no change. Findings vary among more recent studies also, some reporting that most cases improve over time (Rutstein 2003), some that most remain stable (Chia 2005; Kii 1992; Romanchuk 2006) and others that most will deteriorate (Nusz 2005). However all these studies are retrospective reviews of participants who did not have surgery (or follow up until surgery was performed) and criteria for surgical intervention were not standardised, biasing results. Most current teaching texts describe $\mathrm{X}(\mathrm{T})$ as generally being progressive (Mitchell 2000; Santiago 1999; von Noorden 2002), but in the absence of rigorous studies the true natural history of $\mathrm{X}(\mathrm{T})$ remains uncertain.

\section{Presentation and diagnosis}

\section{Clinical characteristics}

The onset of $\mathrm{X}(\mathrm{T})$ is thought to be in the first year of life (Costenbader 1950). The aetiology is unknown although various anatomical, innervational, sensory, and genetic factors have been suggested (Burian 1971; Cooper 1977; Jampolsky 1962). The characteristic features of $\mathrm{X}(\mathrm{T})$ are unique: one eye deviates outward, typically when viewing a distant object, during periods of inattention, in bright sunlight or when the person is tired (Burian 1966). Closure of one eye in bright sunlight, sensitivity to sunlight (Campos 1992; Wang 1988; Wiggins 1990) and panoramic viewing (Cooper 1979; Costenbader 1950) are other common features of $\mathrm{X}(\mathrm{T})$. Diplopia (double vision) appears to be rarely noticed as suppression occurs when the deviation is manifest (Parks 1975; Pratt-Johnson 1969).

Normal use of the eyes together at near fixation (binocular single vision (BSV)) and normal near stereoacuity (three dimensional vision or depth perception) can usually be demonstrated when the exotropia is controlled (Holmes 2007; O'Neal 1995; Stathacopoulos 1993; Yildirim 2000). However, a proportion of people with $\mathrm{X}(\mathrm{T})$ demonstrate subnormal BSV and reduced near stereoacuity (23\% Baker 1979; 31\% Beneish 1994; 11.3\% Yildirim 2000) a feature that is recognised to be part of the spectrum of the disease.

Visual acuity is typically normal in both eyes. A United States study reported amblyopia present only rarely (4.5\%) and a normal distribution of refractive errors (Mohney 2003). Other studies report a higher prevalence of myopia in children with $\mathrm{X}(\mathrm{T})$, compared to the general population (Caltrider 1983). In Asian populations there is a preponderance of myopia (43\%) in children with $\mathrm{X}(\mathrm{T})$ compared to children with esotropia (inward turning strabismus) (Chia 2007).

Intermittent exotropia may be associated with other eye movement anomalies, mainly overaction of the inferior oblique muscle
(Mitchell 2000; Wilson 1989) and lateral incomitance (decrease in amount of exodeviation on sidegaze) (Clarke 1981; Moore 1969; Repka 1991; von Noorden 2002). The reported incidence of lateral incomitance varies (9\% Repka 1991; 22\% Moore 1969; 60\% Clarke 1981) and, importantly, may be erroneously induced as an artifact of testing (Repka 1991). Systemic associations with X(T) include mental illness, a recent study reporting a higher incidence of mental illnesses in patients with $\mathrm{X}(\mathrm{T})$ compared to patients with esotropia and compared to the general population (Mohney 2008).

\section{Diagnostic tests}

A diagnosis of $\mathrm{X}(\mathrm{T})$ is made using the cover test and by measuring the magnitude of exodeviation, typically using the prism cover test. These tests are performed with the subject fixing on an accommodative target at distance fixation and then at near fixation. Cover test shows an intermittent or constant exotropia either at distance fixation only or also at near fixation. Additional measurement of the exodeviation with the subject fixing on a distance target has been recommended to uncover the maximum misalignment (Burian 1971b; Knapp 1960; Kushner 1998b).

Measurement of the exodeviation using the prism cover test at distance and near provides information regarding the degree of misalignment and subtype of $\mathrm{X}(\mathrm{T})$. The basic type of $\mathrm{X}(\mathrm{T})$ shows a similar angle of deviation at distance and near and the distance type of $\mathrm{X}(\mathrm{T})$ shows a greater deviation at distance fixation. The distance type (or 'divergence excess') was originally described as an exodeviation measuring at least 10 prism dioptres greater at distance than near (Burian 1965). The distance type has been subdivided into 'simulated' (pseudo) or 'true' types based on the presence or absence of fusion (motor control of eye position) or focusing mechanisms at near: in the 'simulated' distance $\mathrm{X}(\mathrm{T})$ the near angle of deviation increases, either when fusion is disrupted (by occlusion of one eye) or focusing is relaxed (with plus lenses) (Cooper 1982; Kushner 1998; Walklate 1998) so that, under those conditions, the deviation appears more like the basic type of $\mathrm{X}(\mathrm{T})$. In the 'true' type of distance $\mathrm{X}(\mathrm{T})$ the angle remains smaller at near despite manipulation of focusing and fusing mechanisms. When assessed in this way, 'true' distance $\mathrm{X}(\mathrm{T})$ appears to be relatively uncommon (Kushner 1998; Walklate 1998). Determining whether or not a patient has basic $\mathrm{X}(\mathrm{T})$, simulated distance $\mathrm{X}(\mathrm{T})$, or true distance $\mathrm{X}(\mathrm{T})$ is considered important prior to any surgery, because different surgical approaches have been recommended depending on the subtype (Burian 1965; Hardesty 1978; Kushner 1998a; von Noorden 2002). However, some have suggested that surgery should be based on the distance deviation alone (Mitchell 2000; Stoller 1994).

\section{Severity of $\mathbf{X}(\mathbf{T})$}

Determining the severity of $\mathrm{X}(\mathrm{T})$ relies principally on evaluating: 1) angle of exodeviation, 2) ability to control the exodeviation 
and 3) stereoacuity (as an indicator of the quality of BSV). Traditionally, patients with a large angle of exodeviation and/ or poor control and/ or reduced stereoacuity are considered more severe. However, quantification of severity is poorly standardised.

1. Angle of deviation: There is no clearly defined threshold at which the angle of exodeviation is recognised as more severe. In addition the angle cannot be considered in isolation from ability to control, a small but nearly constant exodeviation presenting a greater threat to binocularity than a large but well controlled exodeviation. There does not appear to be a strong correlation between angle of deviation and ability to control. The threshold for 'real' change in angle is also not well defined. Data in children with esotropia has been reported (PEDIG 2008) but this may not translate to children with $\mathrm{X}(\mathrm{T})$, as there may be greater variability in the underlying condition.

2. Control: Recently developed control scales enable quantification of ability to control the exodeviation at a given point in time (Chia 2005; Haggerty 2004; Mohney 2006; Petrunak 2004; Stathacopoulos 1993). However considerable variation in control is now known to occur (Hatt 2007). Parental observations are often used and are incorporated into some control scales (Haggerty 2004; Stathacopoulos 1993). However these non-standardised observations will vary depending on how much time a parent spends with their child etc.

3. Stereoacuity: Deterioration of near stereoacuity to below normal thresholds, or loss of near stereoacuity, is taken to be a sign of increasing severity, although this is rarely reported. More recently, distance stereoacuity testing has become part of clinical assessment, with deterioration in or loss of distance stereoacuity suggested as a sign of increased severity (O’Neal 1995; Stathacopoulos 1993; Yildirim 1999). Of note, distance stereoacuity may measure as either normal or subnormal in patients with $\mathrm{X}(\mathrm{T})$, depending on the test used (Holmes 2007). Children with X(T) seem to show greater test-retest variability than patients with constant strabismus (Adams 2008). (It is important to remember that some patients with $\mathrm{X}(\mathrm{T})$ have reduced or no measurable stereoacuity at baseline).

\section{Treatment options}

As children with $\mathrm{X}(\mathrm{T})$ do not generally report symptoms such as asthenopia (frontal headaches and eyestrain) or diplopia the aim of treatment is usually to improve ocular alignment whilst maintaining or improving binocular functions and stereoacuity. For this majority of children with $\mathrm{X}(\mathrm{T})$ who are asymptomatic, criteria for intervention are poorly defined. Generally treatment may be offered if physician and/ or parents estimate the amount of time the eyes are misaligned (exotropic) to be equal to or greater than the amount of time they are aligned and working together i.e. exotropia greater than or equal to $50 \%$ of waking hours ( Santiago 1999; von Noorden 2002), based on concerns that, in children, extended periods of misalignment cause suppression to become established, resulting in loss of BSV (Pratt-Johnson 1969).
Intervention may also be instigated when the appearance of the exotropia is causing problems socially, when there is a desire to avoid such social problems, or when there is evidence of loss of stereoacuity.

Treatment may be either surgical, non-surgical or a combination.

\section{Surgical treatment}

Surgery involves adjusting the position or length of the horizontally acting eye muscles. Surgery should result in a complete correction of the exotropia and restoration of normal binocular alignment at distance and near fixation. Most commonly one of the following procedures is undertaken.

1. Two muscle unilateral surgery: the medial rectus muscle (rotates the eye inwards) is strengthened and the lateral rectus muscle (rotates the eye outwards) is weakened.

2. Bilateral surgery: the lateral rectus muscle is weakened on both eyes.

3. One muscle unilateral surgery: one lateral rectus muscle is weakened.

The degree of muscle adjustment is usually tailored to the size of the strabismus although published surgical tables vary. It has been suggested that the effect of a given surgical dose may be influenced by factors such as magnitude of deviation preoperatively, difference between distance and near deviation, and age at time of surgery (Scott 1975). A randomised trial by Kushner (Kushner 1998b) concluded that surgery should aim to correct the maximum horizontal deviation elicited either at far distance or following a period of occlusion, rather than the initial distance measurement. Prism adaptation or vergence aftereffect testing is considered by some to be useful in determining the target angle for surgery (Dadeya 2003; Ohtsuki 2001).

Surgical success rates often appear to be disappointing, with both undercorrection (Clarke 1981; Koo 2006; Richard 1983; Scott 1981) and overcorrection (Dunlap 1971; Edelman 1988; Ing 1999; Pratt-Johnson 1977) recognised as causes of surgical failure. Recurrence of X(T) postoperatively appears a more common cause of failure than overcorrection (Burke 1985) and may occur more frequently over longer periods of follow up (Ekdawi 2008; Maruo 2001). Surgical failure due to persistent overcorrection (inward turning deviation), may cause diplopia, loss of normal BSV, reduction in stereoacuity, and development of amblyopia (lazy eye). Reports of this complication range from 1.5\% (Beneish 1994) to 27\% (Edelman 1988).

Some authors have suggested that successful alignment is more likely when there is an initial overcorrection of the deviation (Hardesty 1978; Keech 1990; Koo 2006; Raab 1969; Scott 1981) that should resolve in the first six weeks following surgery (Mitchell 2000). Others report that a planned initial overcorrection is of no benefit (Ing 1999; Maruo 2001; Pratt-Johnson 1977). The age at surgery is thought by some to influence success: some authorities advocate early intervention to avoid entrenched suppres- 
sion and achieve an optimal result (Abroms 2001; Asjes-Tydeman 2006; Pratt-Johnson 1977; Pratt-Johnson 1994), others suggest that surgery should be delayed until the child is older (Edelman 1988; Richardson 2001; von Noorden 2002; Wickens 1984) and others have concluded that age at surgery makes no difference to the outcome (Beneish 1994; Folk 1956; Ing 1999; Richard 1983; Stoller 1994).

\section{Non-surgical treatment}

Non-surgical treatment aims to encourage use of the eyes together by eliminating suppression (making the brain aware of the visual input from both eyes simultaneously), aiding recognition of diplopia when the eyes are misaligned, and/or building fusional reserves (motor control of the eyes) in order to aid control of the exodeviation.

Non-surgical treatment may consist of the following:

1. Exercises may be used to improve control of the deviation, usually in older children (Cooper 1976; Freeman 1989; Goldrich 1980).

2. Part-time occlusion regimes (Freeman 1989; Flynn 1975; Spoor 1979; Suh 2006) may result in improved control of the deviation, although long-term success is unknown, with some reports noting only a temporary benefit.

3. Minus lens therapy (Caltrider 1983; Rowe 2007; Watts 2005) can be used to induce convergence (inward turning) and therefore reduce the amount of exodeviation. This treatment may be difficult in children with $\mathrm{X}(\mathrm{T})$ who do not otherwise need to wear glasses. Concerns that minus lens therapy may cause or increase myopia (near-sightedness) appear to be unfounded (Kushner 1999; Rutstein 1989).

4. Prisms may be used to correct or overcorrect the exodeviation but often large amounts of prism are required and compliance may be difficult (Hardesty 1978; Pratt-Johnson 1979; Ravault 1972). Other non-surgical treatment:

1. Botulinum toxin injection into the lateral recti has been reported as an alternative to surgery but with varying success (Scott 1990; Spencer 1997).

2. Biofeedback has been described as a non-surgical treatment for $\mathrm{X}(\mathrm{T})$, but does not seem to have been adopted clinically (Goldrich 1982).

\section{Surgery combined with non-surgical treatment}

Using non-surgical treatment as adjunct to surgery pre- and/ or postoperatively has been advocated by some (Coffey 1992; France 1992; Veronneau-Troutman 1971). Pre-surgery, treatment to eliminate suppression and teach awareness of diplopia it is thought to increase the chances of obtaining a cure.

\section{Rationale for a systematic review}

At present there are many different approaches to the management of $\mathrm{X}(\mathrm{T})$ in large part due to a lack of certainty regarding the most effective treatment(s) and when any intervention should be carried out.

\section{O B J E C T I VES}

The primary objective of this review was to determine the effectiveness of surgical and non-surgical treatment of $\mathrm{X}(\mathrm{T})$ in restoring ocular alignment and achieving or maintaining binocular single vision. The effect of factors such as age and sub-type of $\mathrm{X}(\mathrm{T})$ will be reported and if possible included in subgroup analyses.

\section{METHODS}

\section{Criteria for considering studies for this review}

\section{Types of studies}

We included randomised controlled trials that compare management strategies in people with $\mathrm{X}(\mathrm{T})$.

\section{Types of participants}

Participants in the trials were people diagnosed with $\mathrm{X}(\mathrm{T})$ as described under 'Presentation and Diagnosis.' The participants must have evidence of exodeviation on cover test or prism cover test or other recognised method for measuring ocular alignment.

As there is often poor classification of $\mathrm{X}(\mathrm{T})$ and differing nomenclature, any study that did not clearly describe inclusion of basic or distance types of intermittent was excluded. Studies were also excluded if other types of exotropia were included and data on $\mathrm{X}(\mathrm{T})$ could not be extracted, and if participants had received prior treatment.

\section{Types of interventions}

The interventions included were:

1. Surgical:

a. any type of unilateral surgery;

b. any type of bilateral surgery.

2. Non-surgical:

a. fusion/ convergence exercises;

b. occlusion for anti-suppression;

c. optical: minus lens therapy, tinted lenses, prisms;

d. Botulinum toxin A injection.

We examined the following comparisons: 
1. Any surgical intervention versus observation alone.

2. Any non-surgical versus observation alone.

3. Surgical versus any non-surgical.

4. Unilateral versus bilateral surgery.

5. Surgical with any non-surgical adjunct pre- and/ or postoperatively versus surgical without non-surgical adjunct.

6. Unilateral versus unilateral (e.g. one muscle on one eye versus two muscles on one eye).

7. Bilateral versus bilateral (e.g. one muscle on each eye versus two muscles on one eye and one muscle on the other).

8 . Early surgery versus late surgery.

\section{Types of outcome measures}

\section{Primary outcomes}

- motor alignment at near and distance fixation using the simultaneous and/ or alternate prism cover test, or using the synoptophore;

- stereoacuity at near using any age-appropriate test.

\section{Secondary outcomes}

- stereoacuity at distance;

- motor fusion test at near and/ or distance.

Studies with any period of post-treatment follow-up were included but we planned to discuss the potential effects of different lengths of follow up when reporting the results.

\section{Adverse events:}

- overcorrection of the deviation lasting beyond the initial postoperative period with or without symptoms of diplopia;

- development of amblyopia coinciding with postoperative overcorrection;

- complications resulting from non-surgical intervention; or

- intraoperative surgical complications.

We categorised any record of the above adverse effects as severe (requiring further surgery or treatment) or minor (not requiring further intervention).

\section{Quality of life measures:}

We included any measure of patient or parent satisfaction regarding changes in function or appearance.

\section{Search methods for identification of studies}

\section{Electronic searches}

We searched the Cochrane Central Register of Controlled Trials (CENTRAL) (which contains the Cochrane Eyes and Vision Group Trials Register) (The Cochrane Library, Issue 4, 2008), MEDLINE (January 1966 to November 2008), EMBASE (January 1980 to November 2008), the UK Clinical Trials Gateway (UKCTG) and Latin American and Caribbean Literature on Health Sciences (LILACS) (January 1982 to November 2008). There were no language or date restrictions in the search for trials. The electronic databases were last searched on 25 November 2008.

See: Appendices for details of search strategies for CENTRAL (Appendix 1), MEDLINE (Appendix 2), EMBASE (Appendix 3), UKCTG (Appendix 4) and LILACS (Appendix 5).

\section{Searching other resources}

We searched the British Orthoptic Journal from 1970 to 2002 for reports of trials. We also searched the proceedings of the following conferences using the keywords exotropia, intermittent, and divergence excess.

- European Strabismological Association (ESA), 1975 to 1997 and 1999 to 2001;

- International Strabismological Association (ISA), 1994;

- American Academy of Paediatric Ophthalmology and Strabismus meeting (AAPOS) 1995 to 2001.

We searched the reference lists of relevant studies for information on further relevant studies.

Prior to the initial publication of this review in 2003, we contacted researchers (Paediatric Ophthalmology and Strabismus mailbase in USA and UK) active in the field for information about further published or unpublished studies.

\section{Data collection and analysis}

\section{Selection of studies}

Both review authors independently screened the titles and abstracts obtained by the searches to establish whether they met the criteria as defined in 'Criteria for including studies in this review'. We obtained full copies of definitely or potentially relevant studies.

\section{Methods to be used in updates to the review}

Since the first publication of this review we have altered the remit to include a broader definition of intermittent exotropia. This is largely because when going through the original search results we 
identified an obvious overlap between distance and basic subtypes, to the extent that clinically they are often not distinguished from each other and are considered by many clinicians to be essentially the same condition.

We will assess all eligible trials that are identified in future updates of this review according to the following methods.

\section{Data extraction and management}

Trial data will be collected independently by the review authors using a data collection form. We will then check for errors before entering the data in to RevMan.

\section{Assessment of risk of bias in included studies}

Study quality will be assessed according to the methods set out in Chapter 8 of the Cochrane Handbook for Systematic Reviews of Interventions (Higgins 2008). The following parameters will be assessed: sequence generation, allocation concealment, masking (blinding) of participants, personnel and outcome assessors, incomplete outcome data, selective outcome reporting as well as any other sources of bias. For each parameter, for each included trial, we will describe the methods used by study authors to deal with potential bias. These findings will be summarised in the text of the results and also in a risk of bias table. We will also indicate whether the methods employed resulted in a low risk of bias, a high risk of bias or whether it was 'unclear' and we were unable to make a judgement either way. We will attempt to contact the study authors for parameters graded 'unclear.'

Studies where there is a high risk of bias on any parameter will be included and sensitivity analyses conducted to assess the summary effect on the exclusion of these studies.

\section{Data synthesis}

We will summarise data from studies collecting the same outcome measure with similar follow-up. We will use odds ratios or risk ratios for dichotomous data and weighted mean difference for continuous data. We will check for heterogeneity. If no heterogeneity is evident, we will use a random-effects model unless there are fewer than three trials in a comparison, when we will use a fixedeffect model. If heterogeneity is present we will not pool results but will present a descriptive overview of results.

\section{Sensitivity analysis}

Sensitivity analysis will be conducted to assess the size and direction of the effect of excluding trials assessed as inadequate in terms of concealment of randomisation or those with missing data or of questionable eligibility.

\section{R E S U L T S}

\section{Description of studies}

See: Characteristics of included studies; Characteristics of excluded studies.

The electronic searches retrieved a total of 986 titles and abstracts. In light of the amended inclusion criteria; we re-analysed the two papers we excluded in the original published version of the review. Kushner 1998b was still ineligible and was excluded but Kushner 1998a met our inclusion criteria and has been included in the update of the review.

Updated searches

An update search in March 2006 identified 610 new reports of studies. We requested the full text for a total of six studies but was unavailable for two papers (Collur 1998; Rajavi 2001). We attempted to contact the authors for further information but so far this has not been forthcoming and therefore these studies are currently 'awaiting assessment'. If further information becomes available this will be updated otherwise we will exclude these studies in the next update of this review. Three studies required translation: Broniarczyk-loba; Lui 1999 and Zeng 2005. After translation it became apparent that they were not eligible and they were therefore excluded. We excluded the final study Martin 1989 as it was a non-comparative study. For further details of excluded studies please see 'Characteristics of excluded studies' table.

An update search in November 2008 yielded a further 263 reports of studies. The Trials Search Co-ordinator scanned the search results and removed any references which were not relevant to the scope of the review. Two authors independently reviewed the remaining references but did not find any relevant reports of trials. In the included study (Kushner 1998a) 36 patients with basic intermittent exotropia were randomised to two different surgical procedures; bilateral lateral rectus recession or unilateral lateral rectus recession with medial rectus resection. These groups were compared to each other and also to a non-randomised group of 68 patients with simulated distance exotropia who all underwent bilateral lateral recession surgery. The randomised comparison of those with basic intermittent exotropia is reported in this review. Outcomes were assessed at least one year post surgery and recorded as either satisfactory or unsatisfactory; A satisfactory outcome was recorded if there was no tropia and between 10 dioptres exophoria and five dioptres esophoria at any distance on cover and prism cover testing. Any degree of tropia, phoria greater than that stated above (by implication) or any additional treatment was considered an unsatisfactory outcome. Stereoacuity was not reported pre- or postoperatively. The amount of surgery performed was standardised by using surgical formula tables.

\section{Risk of bias in included studies}




\section{Allocation}

The methods used for sequence generation and group allocation are not described in the manuscript. We contacted the author for further details, and clarified that a computer generated random sequence was created and a randomisation assignment was put in a series of sequentially numbered sealed envelopes, the content of which was unknown until after surgery was scheduled and informed consent obtained.

\section{Blinding}

There was no masking of participant or outcome assessor. Outcomes were assessed by the surgeon who performed surgery.

\section{Incomplete outcome data}

Two participants (one from each randomised group) were lost to follow up and were therefore excluded from outcome analysis. All other included participants had complete outcome data.

\section{Selective reporting}

The results section of the manuscript reports that 99 patients were operated on during the study enrolment period, some of whom were excluded because they were recruited for another study ( Kushner 1998b). As it was unclear why or how participants were included in this study rather than the other study and at what point participants were randomised, we contacted the author for further information. Dr Kushner clarified that 29 patients were excluded from the Kushner 1998a study because, according to a predetermined protocol, if they were eligible for the other study (Kushner 1998b) they were automatically selected for recruitment to it. We determined that this did not constitute selective reporting and that there was therefore a low risk of bias for this parameter.

\section{Other potential sources of bias}

Final outcomes were measured 'at least one year' following surgery and varied from 12 to 15 months. It was unclear whether the variability in follow up time was the same for both randomised groups, but further to contact with the author we confirmed that the study follow up time was the same (12 to 15 months) for both randomised groups.

Patients selected for recruitment to this study were those who did not fulfil inclusion criteria for the other randomised study running concurrently (Kushner 1998b). Therefore the group who were eligible for inclusion in Kushner 1998a were those whose exodeviation did not increase after patch or while looking outdoors, representing a subset of the entire basic $\mathrm{X}(\mathrm{T})$ population. This is not spelled out in the manuscript, but has more implications for the generalisability of the results than for conclusions regarding treatment effect.

\section{Effects of interventions}

Nineteen of thirty-six participants were allocated to symmetrical lateral rectus recessions; $17 / 36$ to unilateral lateral rectus recession and medial rectus resection. The range of follow up was 12 to 15 months. Age at surgery and mean angle of distance deviation was comparable between the groups.

Satisfactory results:

Bilateral surgery 10/19 (52\%);

Unilateral surgery $14 / 17$ (82\%).

Unsatisfactory results:

Bilateral surgery 9/19 (48\%): 2/19 (11\%) overcorrected; 7/19

(37\%) undercorrected;

Unilateral surgery 3/17 (18\%): 1/17 (6\%) overcorrected; 2/17 (12\%) undercorrected.

These results were found to be statistically significantly different between the two groups $\left(\mathrm{P}<0.02 ; \mathrm{x}^{2}\right.$ test) favouring unilateral surgery for a successful outcome.

\section{DISCUSSION}

The management of $\mathrm{X}(\mathrm{T})$ is unlike most other types of childhood onset strabismus due to the dual aims of maintaining or improving binocular function (BSV) and correcting the appearance of ocular misalignment. The current literature contains a large body of retrospective case reviews and prospective non-randomised studies which, while useful for describing certain aspects of the condition and it's management, generally do not help establish reliable guidelines for intervention or enable interpretation of treatment effectiveness. We found one randomised trial eligible for inclusion in this review and a summary of the main results and implications are presented below. For an overview of current practice and the evidence on which it is based, the reader is referred to the background section of this review.

\section{Summary of main results}

The included trial by Kushner 1998a studied the effect of two different surgical approaches for correcting the basic type of X(T). A higher proportion of satisfactory outcomes was reported with unilateral recess resect surgery compared to bilateral lateral rectus recession surgery. This finding is consistent with the concept that surgery on the medial and lateral rectus muscles of one eye is appropriate in strabismus where there is little or no near-distance disparity.

Criteria for 'success' following surgery were limited to motor alignment and therefore it is not possible to comment on the effect of surgery on sensory function (stereoacuity): as discussed in earlier sections of this review, surgery can sometimes result in reduction in or loss of stereoacuity. Nevertheless, any manifest strabismus 
was considered an 'unsatisfactory' outcome and therefore it is unlikely that any patient was classified a success in the presence of loss of stereoacuity. Unsuccessful treatment of $\mathrm{X}(\mathrm{T})$ is due to either overcorrection, causing an esodeviation, or undercorrection, causing a residual exodeviation. In the trial by Kushner 1998a 'unsatisfactory' outcomes were more often due to undercorrection of the exodeviation than overcorrection. Some have suggested that a planned, temporary overcorrection in the initial postoperative period will reduce the possibility of undercorrection. However, the initial postoperative eye position was not reported in the included trial so it is unclear whether or not overcorrection played a role in those who were successfully aligned. There do not appear to be rigorous studies assessing the long-term effects of initial surgical overcorrection on postoperative alignment.

\section{Overall completeness and applicability of evidence}

The basic type of $\mathrm{X}(\mathrm{T})$ constitutes a reasonably well defined subgroup of $\mathrm{X}(\mathrm{T})$, but it remains unclear how findings from the included trial may or may not apply to other subgroups of $\mathrm{X}(\mathrm{T})$. If simultaneous surgery on the medial and lateral recti of one eye is indeed more effective where there is little or no difference between the near and distance angle of deviation (near-distance disparity), it may be expected that in true $\mathrm{X}(\mathrm{T})$ where the near-distance disparity persists (larger distance deviation) surgery to both lateral recti would be more effective than unilateral recess/ resect surgery. However we did not find any trials comparing surgical or nonsurgical treatments for the true type of $\mathrm{X}(\mathrm{T})$. We also found no studies comparing treatments for simulated $\mathrm{X}(\mathrm{T})$ so it remains unclear whether or not simulated $\mathrm{X}(\mathrm{T})$ may be treated as basic $\mathrm{X}(\mathrm{T})$ or whether different surgical or non-surgical treatments may be more effective.

The included trial contributes improved evidence for the management of $\mathrm{X}(\mathrm{T})$, but there remain several, major questions and areas in need of further research.

1. Which clinical measures should be used to define severity? Possible measures include angle of deviation, stereoacuity at near and/or distance, control, motor fusion reserves, and quality of life.

\section{What is the natural history of $X(T)$ ?}

It remains unclear what proportion of patients are likely to deteriorate/ improve/ remain stable over time, and whether there are prognostic indicators of deterioration, improvement, or stability. Is the current classification of $\mathrm{X}(\mathrm{T})$ appropriate?

\section{What are appropriate intervention criteria?}

Popular options include reduction in or loss of stereoacuity (at near and/ or distance), deteriorating fusional control, large angle of deviation, or a combination, but potential thresholds remain poorly defined, and current recommendations are not well-validated.

4. Which criteria should be used to define 'success' following treatment?
Various criteria are used in current literature: i) motor alignment only (e.g. within 10 prism dioptres of orthotropia), ii) motor alignment with stereoacuity, or iii) motor alignment with stereoacuity and other motor and sensory capabilities, such as awareness of diplopia when tropic and a normal amplitude of positive motor fusion.

\section{What are realistic long term treatment outcomes?}

The high rates of recurrence reported in some studies question whether it is possible to 'cure' $\mathrm{X}(\mathrm{T})$. It also remains unclear at what point treatment outcomes should be recorded six months, one year, two years etc. following treatment?

\section{What is the role of non-surgical treatment?}

It has been variously suggested that surgical outcomes are optimised if combined with non-surgical treatment, that non-surgical treatments may be as effective as surgery with less risk, and that non-surgical treatment is appropriate only in small angle exodevations. The role of non-surgical treatment and the effectiveness of different types of non-surgical treatment are unclear.

\section{Is early surgery better than late surgery?}

The controversy regarding the optimum age for surgery remains unresolved. The risks associated with early surgery are overcorrection leading to loss of stereoacuity and the development of amblyopia, but the benefits are that successful surgery may be more likely to restore normal binocular alignment. It may be that age at onset or duration affect outcome more than age at surgery, or it may be that each of these does not greatly affect outcome. As yet these issues remain unanswered.

\section{Is unilateral surgery or bilateral surgery more effective?}

It has been suggested that simulated distance exotropia and basic $\mathrm{X}(\mathrm{T})$ should be treated with a unilateral recess resection, and that true distance exotropia should be treated with bilateral lateral rectus recessions. Only one clinical trial (Kushner 1998a) has addressed this issue, and only for the basic type of $\mathrm{X}(\mathrm{T})$.

\section{Is initial postoperative overcorrection advantageous?}

Retrospective studies are divided on whether or not an intial postoperative overcorrection is advantageous. It may be that initial overcorrection plays a role in lasting binocular stability, or initial overcorrection may simply delay inevitable postoperative drift and recurrence of $\mathrm{X}(\mathrm{T})$.

\section{What is the optimal treatment for small angle $X(T)$ ?}

Non-surgical treatment has been advocated, as has a single lateral rectus recession. What constitutes a 'small' angle and whether or not and how it should be treated, remain unclear.

11. What are the effects of $X(T)$ on health related quality of life?

These potential effects are not well described. Such data may be important for guiding the management of the condition and for more clearly defining the benefits versus the risks of surgery.

AUTHORS' CONCLUSIONS 


\section{Implications for practice}

The one randomised study eligible for inclusion in this review found unilateral recess/ resect surgery to be more effective than bilateral recession surgery in correcting basic $\mathrm{X}(\mathrm{T}$. This provides some guidance for this subgroup of $\mathrm{X}(\mathrm{T})$ but generally there remains a significant lack of reliable evidence to help inform practice. In the absence of good evidence of treatment effectiveness, the potential to do harm by correcting the appearance of misalignment but disrupting the ability to maintain BSV should be seriously considered when managing this condition.

\section{Implications for research}

There is a clear need for further randomised studies to provide more reliable evidence for the management of this condition. In particular to:

- establish the natural history of the condition;

- clarify appropriate intervention criteria for non-surgical and surgical treatments;

- improve methods to measure severity;

- identify the most effective surgical procedure for different types of $\mathrm{X}(\mathrm{T})$, for example simulated and true distance $\mathrm{X}(\mathrm{T})$;
- establish realistic treatment aims and long-term outcomes;

- determine influence of age/ duration of misalignment on outcome;

- establish effectiveness of non-surgical treatments;

- identify whether or not initial overcorrection is advantageous in achieving optimal treatment outcomes;

- measure effects of X(T) on quality of life.

\section{ACKNOWLEDGEMENTS}

The Cochrane Eyes and Vision Group developed and executed the electronic search strategies. We are grateful to Sue Elliott, Roberta Scherer and Catey Bunce for peer review comments on this review. We also wish to thank Dr Burton J Kushner for his help in providing additional information regarding the included study. In addition we thank Maoling Wei, Atsumi Hirose and Dr. Piotr Powazka for their help with translating non-English articles.

\section{REF ER E N C E S}

\section{References to studies included in this review}

Kushner 1998a \{published data only\}

Kushner BJ. Selective surgery for intermittent exotropia based on distance/ near differences. Archives of Ophthalmology 1998;116(3):324-8.

\section{References to studies excluded from this review}

Broniarczyk-loba \{published data only\}

* Broniarczyk-loba A, Nowakowska O. Adjustable sutures surgery of intermittent divergent squint in adolescents and adults [Operacyjne leczenie zezow rozbieznych okresowych u mtodziezy i dorostytch metoda szwow regulowanych]. Klinika Oczna 2003;105(1-2):63-5.

Kushner 1998b \{published data only\}

Kushner BJ. The distance angle to target in surgery for intermittent exotropia. Archives of Ophthalmology 1998;116 (2):189-94.

Lui 1999 \{published data only\}

* Lui S, Wu X, Xai X. An approach to treat child intermittent exotropia with extraordinary recession of the external rectus. Hunan-Yi-Ke-Da-Xue-Xue-Bao 1999;24(1): $87-8$.

Martin 1989 \{published data only\}

Martin LP. The effect of lateral incomitance in intermittent exotropia. British Orthoptic Journal 1989;46:49-57.
Zeng 2005 \{published data only\}

Zeng S, Yan Y, Chen Q, Li M, Lai Y. Binocular vision rebuilding in patients with intermittent exotropia operation followed by fusion function training. International Journal Ophthalmology (Gouji Yanke Zazhi) 2005;5(5):958-60.

\section{References to studies awaiting assessment}

\section{Collur 1998 \{published data only\}}

Collur S, Prakesh B, Strominger MB. Dominant versus non dominant eye muscle surgery for exotropia. American Academy of Ophthalmology 1998:160.

Rajavi 2001 \{published data only\}

Rajavi Z, Moezzi-Ghadim H, Hamidi S. The results of bilateral rectus recession and unilateral recess resect on basic exotropia. American Academy of Ophthalmology 2001:227.

\section{Additional references}

\section{Abroms 2001}

Abroms AD, Mohney BG, Rush DP, Parks MM, Tong PY. Timely surgery in intermittent and constant exotropia for superior sensory outcome. American Journal of Ophthalmology 2001;131(1):111-6. 


\section{Adams 2008}

Adams W, Leske DA, Hatt SR, Holmes JM. Defining real change in measures of stereoacuity. Ophthalmology 2009; 116(2):281-5.

\section{Asjes-Tydeman 2006}

Asjes-Tydeman WL, Groenewoud H, van der Wilt GJ. Timing of surgery for primary exotropia in children. Strabismus 2006;14(4):191-7.

\section{Baker 1979}

Baker JD, Davies GT. Monofixational intermittent exotropia. Archives of Ophthalmology 1979;97(1):93-5.

\section{Beneish 1994}

Beneish R, Flanders M. The role of stereopsis and early postoperative alignment in long term surgical results of intermittent exotropia. Canadian Journal of Ophthalmology 1994;29(3):119-24.

\section{Burian 1965}

Burian HM, Spivey BE. The surgical management of exodeviations. American Journal of Ophthalmology 1965;59: 603.

\section{Burian 1966}

Burian HM. Exodeviations: their classification, diagnosis and treatment. American Journal of Ophthalmology 1966;62 (6):1161-6.

\section{Burian 1971}

Burian HM. Pathophysiology of exo deviations. In: Manley DR editor(s). Symposium on horizontal ocular deviations. St Louis: Mosby Year Book, 1971:119.

\section{Burian 1971b}

Burian HM. Transactions of American Ophthalmological Society annual meeting. Whiting Press, 1971:188-99.

\section{Burke 1985}

Burke MJ. Intermittent exotropia. International Ophthalmology Clinics 1985;25:53-68.

\section{Caltrider 1983}

Caltrider N, Jampolsky A. Overcorrecting minus lens therapy for treatment of intermittent exotropia. Ophthalmology 1983;90(10):1160-5.

\section{Campos 1992}

Campos EC, Cipolli C. Binocularity and photophobia in intermittent exotropia. Perceptual and Motor Skills 1992;74 (3 Pt 2):1168-70.

\section{Chia 2005}

Chia A, Seenyen L, Long QB. A retrospective review of 287 consecutive children in Singapore presenting with intermittent exotropia. Journal of AAPOS: American Association for Pediatric Ophthalmology \& Strabismus 2005;9 (3):257-63.

\section{Chia 2007}

Chia A, Roy L, Seenyen L. Comitant horizontal strabismus: an Asian perspective. British Journal of Ophthalmology 2007; 91(10):1337-40.

\section{Clarke 1981}

Clarke WN, Noel LP. Surgical results in intermittent exotropia. Canadian Journal of Ophthalmology 1981;16(2): 66-9.

\section{Coffey 1992}

Coffey B, Wick B, Cotter S, Scharre J, Horner D. Treatment options in intermittent exotropia: a critical appraisal. Optometry \& Vision Science 1992;69(5):386-404.

\section{Cooper 1976}

Cooper EL, Leyman IA. The management of intermittent exotropia. A comparison of the results of surgical and non surgical management. Orthoptics: past present and future. Transactions of the 3rd International Orthoptic Congress. New York: Stratton Intercontinental Medical Book Corp, 1976.

Cooper 1977

Cooper J. Intermittent exotropia of the divergence excess type. Journal of the American Optometric Association 1977; 48(10): 1261-73.

\section{Cooper 1979}

Cooper J, Feldman J. Panoramic viewing, visual acuity of the deviating eye, and anomalous retinal correspondence in the intermittent exotrope of the divergence excess type. American Journal of Optometry \& Physiological Optics 1979; 56(7):422-9.

\section{Cooper 1982}

Cooper J, Ciuffreda KJ, Kruger PB. Stimulus and response $\mathrm{AC} / \mathrm{A}$ ratios in intermittent exotropia of the divergenceexcess type. British Journal of Ophthalmology 1982;66(6): 398-404.

\section{Costenbader 1950}

Costenbader FD. The physiology and management of divergent strabismus. In: Allen JH editor(s). Strabismic Ophthalmic Symposium. St Louis: Mosby Year Book, 1950: 353.

\section{Dadeya 2003}

Dadeya S, Kamlesh, Naniwal S. Usefulness of the preoperative prism adaptation test in patients with intermittent exotropia. Journal of Pediatric Ophthalmology \& Strabismus 2003;40(2):85-9.

\section{Dunlap 1971}

Dunlap EA. Overcorrections in horizontal strabismus surgery. Symposium on Strabismus. Transactions of the New Orleans Academy of Ophthalmology. St Louis: Mosby Year Book, 1971:255.

\section{Edelman 1988}

Edelman PM, Brown MH, Murphree AL, Wright KW. Consecutive esodeviation ... Then what?. American Orthopic Journal 1988;38:111-6.

\section{Ekdawi 2008}

Ekdawi NS, Nusz KJ, Diehl NN, Mohney BG. Postoperative outcomes in children with intermittent exotropia from a population-based cohort. Journal American Academy Pediatric Ophthalmology \& Strabismus 2008 Oct 10;Epub ahead of print. 
Flynn 1975

Flynn JT, McKenney S, Rosenhouse M. A method of feating intermittent divergence strabismus [Eine Behandlungs form des intermittierenden Divergenzschielens]. Klinische Monatsblatter fur Augenheilkunde 1975;167(2):185-90.

\section{Folk 1956}

Folk ER. Surgical results in intermittent exotropia. $A M A$ Archives of Ophthalmology 1956;55(4):484-7.

\section{France 1992}

France LW. The role of orthoptic therapy in exodeviations: a basis for orthoptic referral. American Orthoptic Journal 1992;42:52-64.

\section{Freeman 1989}

Freeman RS, Isenberg SJ. The use of part-time occlusion for early onset unilateral exotropia. Journal of Pediatric Ophthalmology \& Strabismus 1989;26(2):94-6.

\section{Glanville 2006}

Glanville JM, Lefebvre C, Miles JN, Camosso-Stefinovic J. How to identify randomized controlled trials in MEDLINE: ten years on. Journal of the Medical Library Association 2006; 94(2):130-6.

\section{Goldrich 1980}

Goldrich SG. Optometric therapy of divergence excess strabismus. American Journal of Optometry \& Physiological Optics 1980;57(1):7-14.

\section{Goldrich 1982}

Goldrich SG. Oculomotor biofeedback therapy for exotropia. American Journal of Optometry \& Physiological Optics 1982;59(4):306-17.

\section{Govindan 2004}

Govindan M, Mohney BG, Diehl NN, Burke JP. Incidence and types of childhood exotropia. Ophthalmology 2005;112 (1):104-8

Graham 1974

Graham PA. Epidemiology of strabismus. British Journal of Ophthalmology 1974;58(3):224-31.

Haggerty 2004

Haggerty H, Richardson S, Hrisos S, Strong NP, Clarke MP. The Newcastle Control Score: a new method of grading the severity of intermittent distance exotropia. British Journal of Ophthalmology 2004;88(2):233-5.

\section{Hardesty 1978}

Hardesty HH, Boynton JR, Keenan JP. Treatment of intermittent exotropia. Archives of Ophthalmology 1978;96 (2):268-74

\section{Hatt 2007}

Hatt SR, Mohney BG, Leske DA, Holmes JM. Variability of control in intermittent exotropia. Ophthalmology 2007; 115(2):371-6.

\section{Higgins 2008}

Higgins JPT, Altman DG (editors). Chapter 8: Assessing risk of bias in included studies. In: Higgins JPT, Green $S$ (editors). Cochrane Handbook for Systematic Reviews of Interventions Version 5.0.0 (updated February 2008).
The Cochrane Collaboration, 2008. Available from www.cochrane-handbook.org.

\section{Hiles 1968}

Hiles DA, Davies GT, Costenbader FD. Long-term observations of unoperated intermittent exotropia. Archives of Ophthalmology 1968;80(4):436-42.

Holmes 2007

Holmes JM, Birch EE, Leske DA, Fu VL, Mohney BG. New tests of distance stereoacuity and their role in evaluating intermittent exotropia. Ophthalmology 2007;114 (6):1215-20.

Ing 1999

Ing MR, Nishimura J, Okino L. Outcome study of unilateral lateral rectus recession for intermittent exotropia in children. Ophthalmic Surgery \& Lasers 1999;30(2): $110-7$.

\section{Jampolsky 1962}

Jampolsky A. Management of exodeviations. Strabismus. Symposium of the New Orleans Academy of Ophthalmology. St Louis: Moseby Year Book, 1962.

\section{Jenkins 1992}

Jenkins R. Demographics geographic variations in the prevalence and management of exotropia. American Orthoptic Journal 1992;42:82-7.

\section{Keech 1990}

Keech RV, Stewart SA. The surgical overcorrection of intermittent exotropia. Journal of Pediatric Ophthalmology \& Strabismus 1990;27(4):218-20.

\section{Kii 1992}

Kii T, Nakagawa T. Natural history of intermittent exotropia - statistical study of preoperative strabismuc angle in different age groups. Nippon Ganka Gakkai Zasshi 1992; 96:904-9.

\section{Knapp 1960}

Knapp P, Moore S. Intermittent exotropia. American Orthoptic Journal 1960;10:118-22.

Koo 2006

Koo NK, Lee YC, Lee SY. Clinical study for the undercorrection factor in intermittent exotropia. Korean Journal of Ophthalmology 2006;20(3):182-7.

\section{Kushner 1998}

Kushner BJ, Morton GV. Distance / near differences in intermittent exotropia. Archives of Ophthalmology 1998;116 (4):478-86.

Kushner 1998b

Kushner BJ. The distance angle to target in surgery for intermittent exotropia. Archives of Ophthalmology 1998;116 (2):189-94

Kushner 1999

Kushner BJ. Does overcorrecting minus lens therapy for intermittent exotropia cause myopia?. Archives of Ophthalmology 1999;117(5):638-42.

\section{Maruo 2001}

Maruo T, Kubota N, Sakaue T, Usui C. Intermittent exotropia surgery in children: long term outcome regarding 
changes in binocular alignment. A study of 666 cases. Binocular Vision \& Strabismus Quarterly 2001;16(4): 265-70.

\section{Matsuo 2005}

Matsuo T, Matsuo C. The prevalence of strabismus and amblyopia in Japanese elementary school children. Ophthalmic Epidemiology 2005;12(1):31-6.

\section{Mitchell 2000}

Mitchell PR, Parks MM. Concomitant exodeviations. Clinical Ophthalmology. Philadelphia, PA: Harper Row \& Company, 2000:(chapter 13) 1-17.

\section{Mohney 2003}

Mohney B, Huffaker RK. Common forms of childhood exotropia. Ophthalmology 2003;110(11):2093-6.

\section{Mohney 2006}

Mohney BG, Holmes JM. An office-based scale for assessing control in intermittent exotropia. Strabismus 2006;14(3): $147-50$.

\section{Mohney 2008}

Mohney BG, McKenzie JA, Capo JA, Nusz KJ, Mrazek D, Diehl NN. Mental illness in young adults who had strabismus as children. Pediatrics 2008;122(5):1033-8.

\section{Moore 1969}

Moore S. The prognostic value of lateral gaze measurements in intermittent exotropia. American Orthoptic Journal 1969; 19:69-71.

\section{Nusz 2005}

Nusz KJ, Mohney BJ, Diehl N. Female predominance in intermittent exotropia. American Journal of Ophthalmology 2005;140(3):546-7.

O’Neal 1995

O’Neal TD, Rosenbaum AL, Stathacopoulos RA. Distance stereoacuity improvement in intermittent exotropic patients following strabismus surgery. Journal of Pediatric Ophthalmology \& Strabismus 1995;32(6):353-7.

\section{Ohtsuki 2001}

Ohtsuki H, Hasebe S, Kono R, Yamane T, Fujiwara H, Shiraga F. Prism adaptation response is useful for surgical outcome in selected types of intermittent exotropia. American Journal of Ophthalmology 2001;131(1):117-22.

\section{Parks 1975}

Parks M. Sensorial adaptations in strabismus. In: Thomas D Duane editor(s). Ocular motility and strabismus. Hagerstown: Harper \& Row, 1975:67.

\section{PEDIG 2008}

Pediatric Eye Disease Investigator Group. Christiansen SP, Chandler DL, Holmes JM, Arnoldi RW, Birch E, Daqi LR, et al.Instability of ocular alignment in childhood esotropia. Ophthalmology 2008;115(12):2266-74.

\section{Petrunak 2004}

Petrunak JL, Rao RC, Baker JD. The evaluation of office control in $\mathrm{X}(\mathrm{T})$ : A systematic approach. Transactions of the 28th European Strabismological Association Meeting. London: Taylor and Francis, 2004:109-12.
Pratt-Johnson 1969

Pratt-Johnson J, Wee HS. Suppression associated with exotropia. Canadian Journal of Ophthalmology 1969;4(2): $136-44$.

\section{Pratt-Johnson 1977}

Pratt-Johnson JA, Barlow JM, Tillson G. Early surgery in intermittent exotropia. American Journal of Ophthalmology 1977;84(5):689-94.

Pratt-Johnson 1979

Pratt-Johnson JA. Tillson G. Prismotherapy in intermittent exotropia. Canadian Journal of Ophthalmology 1979;14(4): 243-5.

\section{Pratt-Johnson 1994}

Pratt-Johnson JA, Tillson G. Management of strabismus and amblyopia: a practical guide. New York Stuttgart: Thieme, 1994:128.

\section{Raab 1969}

Raab EL, Parks MM. Recession of the lateral recti. Early and late postoperative alignments. Archives of Ophthalmology 1969;82(2):203-8.

\section{Ravault 1972}

Ravault AP, Bongrand G, Bonamour G. The utilization of prisms in the treatment of divergent strabismus. Orthoptics. Proceedings of the 2nd International Orthoptics Congress. Amsterdam: Excerpta Medica Foundation, 1972:77.

\section{Repka 1991}

Repka MX, Arnoldi KA. Lateral incomitance in exotropia: fact or artifact?. Journal of Pediatric Ophthalmology \& Strabismus 1991;28(3):125-30.

\section{Richard 1983}

Richard JM, Parks MM. Intermittent exotropia. Surgical results in different age groups. Ophthalmology 1983;90(10): $1172-7$.

\section{Richardson 2001}

Richardson $S$. When is surgery indicated for distance exotropia?. British Orthoptic Journal 2001;58:24-9.

\section{Romanchuk 2006}

Romanchuk KG, Dotchin SA, Zurevinsky J. The natural history of surgically untreated intermittent exotropia - looking into the distance future. Journal of AAPOS: American Association for Pediatric Ophthalmology \& Strabismus 2006;10(3):225-31.

Rowe 2007

Rowe FJ, Noonan CP, Freeman G, Debell J. Intervention for intermittent distance exotropia with overcorrecting minus lenses. Eye 2007 Dec 7;Epub ahead of print.

\section{Rutstein 1989}

Rutstein RP, Marsh-Tootle W, London R. Changes in refractive error for exotropes treated with overminus lenses. Optometry \& Vision Science 1989;66(8):487-91.

\section{Rutstein 2003}

Rutstein RP, Corliss DA. The clinical course of intermittent exotropia. Optometry \& Vision Science 2003;80(9):644-9. 


\section{Santiago 1999}

Santiago AP, Ing MR, Kushner BJ, Rosenbaum AL. Intermittent Exotropia. In: Rosenbaum AL, Santiago AP editor(s). Clinical Strabismus Management. Principles and Surgical Techniques. Philadelphia, PA: WB Saunders Company, 1999:163-75.

\section{Scott 1975}

Scott AB, Mash JA, Jampolsky A. Quantitative guidelines for exotropia surgery. Investigative Ophthalmology 1975;14 (6):428-36.

Scott 1981

Scott WE, Keech R, Mash AJ. The postoperative results and stability of exodeviations. Archives of Ophthalmology 1981; 99(10):1814-8.

\section{Scott 1990}

Scott AB, Magoon EH, McNeer KW, Stager DR. Botulinum treatment of childhood strabismus. Ophthalmology 1990;97 (11):1434-8.

\section{Spencer 1997}

Spencer RF, Tucker MG, Choi RY, McNeer KW. Botulinum Toxin management of childhood intermittent exotropia. Ophthalmology 1997;104(11):1762-7.

\section{Spoor 1979}

Spoor DK, Hiles DA. Occlusion therapy for exodeviations occurring in infants and young children. Ophthalmology 1979;86(12):2152-7.

\section{Stathacopoulos 1993}

Stathacopoulos RA, Rosenbaum AL, Zanoni D, Stager DR, McCall LC, Ziffer AJ, et al.Distance stereoacuity. Assessing control in intermittent exotropia. Ophthalmology 1993;100 (4):495-500.

\section{Stoller 1994}

Stoller SH, Simon JW, Lininger LL. Bilateral rectus recession for exotropia: a survival analysis. Journal of Pediatric Ophthalmology \& Strabismus 1994;31(2):89-92.

\section{Suh 2006}

Suh YW, Kim SH, Lee JL, Cho YA. Conversion of intermittent exotropia types subsequent to part time occlusion. Graefes Archive for Clinical \& Experimental Ophthalmology 2006;244(6):705-8.

Veronneau-Troutman 1971

Veronneau-Troutman S. Intermittent exotropia. International Ophthalmology Clinics 1971;11(4):114-9.

\section{von Noorden 1966}

von Noorden GK. Some aspects of exotropia. Presented at Wilmers Residents' Association, John Hopkins Hospital, Baltimore April 261966.

von Noorden 2002

von Noorden GK, Campos EC. Binocular Vision and Ocular Motility: Theory and Mangement of Strabismus. 6th Edition. St Louis, Missouri: Mosby, Inc, 2002:356-376.

\section{Walklate 1998}

Walklate $\mathrm{K} \mathrm{J}$. The role of diagnostic occlusion in distance exotropia. British Orthoptic Journal 1998;55:2-7.

\section{Wang 1988}

Wang FM, Chryssanthou CO. Monocular eye closure in intermittent exotropia. Archives of Ophthalmology 1998;106 (7):941-2.

\section{Watts 2005}

Watts P, Tippings E, Al-Madfai H. Intermittent exotropia, overcorrecting minus lenses, and the Newcastle scoring system. Journal of AAPOS: American Association for Pediatric Ophthalmology \& Strabismus 2005;9(5):460-4.

\section{Wickens 1984}

Wickens R. Results of surgery in distance exotropia. British Orthoptic Journal 1984;41:66-72.

\section{Wiggins 1990}

Wiggins RE, von Noorden GK. Monocular eye closure in sunlight. Journal of Pediatric Ophthalmology \& Strabismus 1990;27(1):16-20.

\section{Wilson 1989}

Wilson ME, Parks MM. Primary inferior oblique overaction in congenital esotropia, accommodative esotropia and intermittent exotropia. Ophthalmology 1989;96(7):950-7.

\section{Yildirim 1999}

Yildirim C, Mutulu FM, Chen Y, Altinsoy HI. Assessment of central and peripheral fusion and near and distance stereoacuity in intermittent exotropia patients before and after strabismus surgery. American Journal of Ophthalmology 1999;128(2):222-30.

Yildirim 2000 Yildirim C, Altinsoy HI. Distance alternate-letter suppression test for objective assessment of sensorial status in intermittent exotropia. European Journal of Ophthalmology 2000;10(1):4-10.

* Indicates the major publication for the study 


\section{CHARACTERISTICS OF STUDIES}

\section{Characteristics of included studies [ordered by study ID]}

\section{Kushner 1998a}

\begin{tabular}{|c|c|c|}
\hline Methods & \multicolumn{2}{|c|}{ Randomised trial comparing 2 different surgical interventions for basic $\mathrm{X}(\mathrm{T})$} \\
\hline Participants & \multicolumn{2}{|c|}{ Children diagnosed with basic $\mathrm{X}(\mathrm{T})$ : near deviation within 10 dioptres of distance } \\
\hline Interventions & \multicolumn{2}{|c|}{$\begin{array}{l}\text { Bilateral lateral rectus recession or unilateral lateral rectus recession with medial rectus } \\
\text { resection }\end{array}$} \\
\hline Outcomes & \multicolumn{2}{|c|}{$\begin{array}{l}\text { At a minimum of } 1 \text { year post surgery ( } 12 \text { to } 15 \text { months): } \\
\text { Satisfactory: between } 10 \text { dioptres exophoria and } 5 \text { dioptres esophoria } \\
\text { Unsatisfactory: any manifest deviation or post-operative treatment }\end{array}$} \\
\hline Notes & \multicolumn{2}{|c|}{$\begin{array}{l}\text { 'Control' group also included in study but not reported here as comprises a different } \\
\text { subgroup of } \mathrm{X}(\mathrm{T}) \text { all undergoing same surgical procedure }\end{array}$} \\
\hline \multicolumn{3}{|l|}{ Risk of bias } \\
\hline Item & Authors' judgement & Description \\
\hline Adequate sequence generation? & Yes & $\begin{array}{l}\text { The methods used for sequence generation } \\
\text { are not described in the manuscript. We } \\
\text { contacted the author for further details and } \\
\text { clarified that a computer generated random } \\
\text { sequence was created }\end{array}$ \\
\hline Allocation concealment? & Yes & $\begin{array}{l}\text { It is unclear in the manuscript whether or } \\
\text { not there was concealment of treatment } \\
\text { allocation. We contacted the author who } \\
\text { clarified that the randomisation assignment } \\
\text { was put in a series of sequentially numbered } \\
\text { sealed envelopes, the content of which was } \\
\text { unknown until after surgery was scheduled } \\
\text { and informed consent obtained }\end{array}$ \\
\hline $\begin{array}{l}\text { Blinding? } \\
\text { All outcomes }\end{array}$ & No & $\begin{array}{l}\text { There was no masking of participant or } \\
\text { outcome assessor. Outcomes were assessed } \\
\text { by the surgeon who performed surgery }\end{array}$ \\
\hline $\begin{array}{l}\text { Incomplete outcome data addressed? } \\
\text { All outcomes }\end{array}$ & Yes & $\begin{array}{l}2 \text { participants ( } 1 \text { from each randomised } \\
\text { group) were lost to follow and were there- } \\
\text { fore excluded from outcome analysis. All } \\
\text { other included participants had complete } \\
\text { outcome data }\end{array}$ \\
\hline
\end{tabular}


Free of selective reporting?

Yes

Free of other bias?

Yes
99 patients were operated on during the study enrolment period, some of whom were excluded because they were recruited for another study (Kushner 1998b). As it was unclear why or how participants were included in this study rather than the other study and at what point participants were randomised, we contacted the author for further information: $29 \mathrm{pa}-$ tients were excluded from Kushner 1998a because, according to a predetermined protocol, if they were eligible for the other study (Kushner 1998b) they were automatically selected for recuitment to it. We determined that this did not constitute selective reporting

Final outcomes were measured 'at least one year' following surgery and varied from 12 to 15 months across the entire study population. Further to communication with the author, we clarified that the follow up was 12 to 15 months for each randomised group

Patients selected for recruitment to this study were those who did not fulfil inclusion criteria for another randomised study running concurrently (Kushner 1998b). Therefore the group who were eligible for inclusion in Kushner 1998a were those whose exodeviation did not increase after patching or while looking outdoors, representing a subset of the entire basic $\mathrm{X}(\mathrm{T})$ population. This is not spelled out in the manuscript, but has more implications for the generalisability of the results and is not likely to bias conclusions regarding treatment effect

$\mathrm{X}(\mathrm{T})$ : intermittent exotropia 
Characteristics of excluded studies [ordered by study ID]

\begin{tabular}{ll}
\hline Study & Reason for exclusion \\
\hline Broniarczyk-loba & Prospective study comparing two surgical techniques but non-randomised allocation* \\
\hline Kushner 1998b & $\begin{array}{l}\text { Randomised controlled trial comparing surgery for the basic distance angle or the maximum distance angle } \\
\text { elicited post occlusion: this comparison was not relevant to this review }\end{array}$ \\
\hline Lui 1999 & Observational study* \\
\hline Martin 1989 & Non-comparative study looking at the effect of lateral incommitance on intermittent exotropia outcomes \\
\hline Zeng 2005 & Non randomised study*. \\
\hline
\end{tabular}

* studies requiring translation 


\section{DATA ANDANALYSES}

This review has no analyses.

\section{A P PEN DICES}

\section{Appendix I. CENTRAL search strategy}

\#1 MeSH descriptor Exotropia

\#2 MeSH descriptor Strabismus

\#3 Divergen* ${ }^{*}$ and (excess* or strabismus)

\#4 Exotrop* or IDEX

\#5 Intermitten* and exotrop*

\#6 Ocular* and (misalignment or deviat*)

\#7 (\#1 OR \#2 OR \#3 OR \#4 OR \#5 OR \#6)

\section{Appendix 2. MEDLINE search strategy}

1 randomized controlled trial.pt.

2 (randomized or randomised).ab,ti.

3 placebo.ab,ti.

$4 \mathrm{dt} . \mathrm{fs}$.

5 randomly.ab,ti.

6 trial.ab,ti.

7 groups.ab,ti.

8 or/1-7

9 exp animals/

10 exp humans/

119 not (9 and 10)

128 not 11

13 exp exotropia/

14 exp strabismus/

15 ((excess\$ or strabism\$) adj10 diverge\$).tw.

16 (exotrop\$ or IDEX).tw.

17 (intermitt\$ adj10 exotrop\$).tw.

18 ((misalig\$ or deviat\$) adj10 ocular\$).tw.

19 or/13-18

2012 and 19

The search filter for trials at the beginning of the MEDLINE strategy is from the published paper by Glanville (Glanville 2006). 


\section{Appendix 3. EMBASE search strategy}

1 exp randomized controlled trial/

2 exp randomization/

3 exp double blind procedure/

4 exp single blind procedure/

5 random $\$$.tw.

6 or/ $1-5$

7 (animal or animal experiment).sh.

8 human.sh.

97 and 8

107 not 9

116 not 10

12 exp clinical trial/

13 (clin\$ adj3 trial\$).tw.

14 ((singl\$ or doubl\$ or trebl\$ or tripl\$) adj3 (blind\$ or mask\$)).tw.

15 exp placebo/

16 placebo\$.tw.

17 random\$.tw.

18 exp experimental design/

19 exp crossover procedure/

20 exp control group/

21 exp latin square design/

22 or/ $12-21$

2322 not 10

2423 not 11

25 exp comparative study/

26 exp evaluation/

27 exp prospective study/

28 (control\$ or prospectiv\$ or volunteer\$).tw.

29 or $/ 25-28$

3029 not 10

3130 not (11 or 23$)$

3211 or 24 or 31

33 exp divergent strabismus/

34 exp strabismus surgery/

35 ((excess\$ or strabism\$) adj10 diverge\$).tw.

36 (exotrop\$ or IDEX).tw.

37 (intermitt\$ adj10 exotrop\$).tw.

38 ((misalig\$ or deviat\$) adj10 ocular\$).tw.

39 or $/ 33-38$

4032 and 39 


\section{Appendix 4. UK Clinical Trials Gateway (UKCTG) search strategy}

intermitt $\%$ and exotrop $\%$

\section{Appendix 5. LILACS search strategy}

intermitt\$ and exotrop\$

\section{WHAT'S NEW}

Last assessed as up-to-date: 24 November 2008.

\begin{tabular}{l|l|l}
\hline Date & Event & Description \\
\hline 30 January 2009 & New search has been performed & $\begin{array}{l}\text { Issue 2, 2009: updated search yielded no new trials. The background section } \\
\text { has been updated }\end{array}$ \\
\hline
\end{tabular}

\section{H I S T O R Y}

Protocol first published: Issue 3, 2002

Review first published: Issue 2, 2003

\begin{tabular}{lll}
\hline Date & Event & Description \\
\hline 16 May 2008 & Amended & Converted to new review format. \\
\hline 24 May 2006 & New search has been performed & $\begin{array}{l}\text { The updated version of this review includes a broader spec- } \\
\text { trum of intermittent exotropia: initially we restricted inclu- } \\
\text { sion to studies specifying intermittent distance exotropia. } \\
\text { However in many cases distance and basic types of intermit- } \\
\text { tent exotropia are not differentiated from each other and are } \\
\text { pooled together. This is consistent with clinical observations } \\
\text { which often show an individual to change from distance to } \\
\text { basic from visit to visit } \\
\text { In light of the amended inclusion criteria, one study previ- } \\
\text { ously excluded, now qualifies for inclusion }\end{array}$ \\
\hline 24 May 2006 & New citation required and conclusions have changed & \begin{tabular}{l} 
Substantive amendment. \\
\hline
\end{tabular}
\end{tabular}




\section{CONTRIBUTIONSOFAUTHORS}

Sarah Hatt and Lawrence Gnanaraj were both responsible for:

Designing the review

Data collection for the review

Screening search results

Screening retrieved papers against inclusion criteria

Appraising quality of papers

Abstracting data from papers

Writing to authors of papers for additional information

Obtaining and screening data on unpublished studies

Data management for the review

Entering data into RevMan

Analysis of data

Interpretation of data

Writing the review

Sarah Hatt was also responsible for co-ordinating the review.

\section{DECLARATIONSOF INTEREST}

None known.

\section{NDEX TERMS}

Medical Subject Headings (MeSH)

Exotropia [ ${ }^{*}$ surgery; therapy]; Randomized Controlled Trials as Topic

\section{MeSH check words}

Humans 